\title{
Pengaruh Pendapatan Orangtua terhadap Kualitas Hidup Pasien Epilepsi Anak
}

Monika Putri Gratia, Fadhilah Tia Nur, Muhammad Riza

Departemen Ilmu Kesehatan Anak Fakultas Kedokteran Universitas Sebelas Maret/RS Dr Moewardi, Surakarta

Latar belakang. Kualitas hidup seseorang berkaitan dengan kondisi kesehatannya. Anak penderita epilepsi cenderung memiliki kualitas hidup yang buruk. Kualitas hidup rendah pasien epilepsi anak dipengaruhi oleh beragam faktor, salah satunya dari segi demografis keluarga, yaitu besar pendapatan orangtua.

Tujuan. Mengetahui pengaruh pendapatan orangtua terhadap kualitas hidup pasien epilepsi anak di RSUD Dr. Moewardi Surakarta, menggunakan instrumen PedsQL.

Metode. Penelitian ini merupakan penelitian observasional analitik dengan pendekatan potong lintang. Pengambilan sampel dilakukan di poli saraf anak Wijaya Kusuma RSUD Dr. Moewardi, melibatkan wawancara pada 50 pasien epilepsi anak beserta orangtuanya.

Hasil. Pasien epilepsi anak sebagian besar (66.0\%) memiliki kualitas hidup yang rendah. Pendapatan orangtua dinyatakan tidak signifikan memengaruhi kualitas hidup pasien epilepsi anak $(\mathrm{p}=0,281)$. Kualitas hidup pasien dipengaruhi oleh jenis pemberian OAE dan kepesertaan BPJS ( $\mathrm{p}=0,001 ; \mathrm{p}=0,040)$.

Kesimpulan. Tidak terdapat pengaruh dari pendapatan orangtua terhadap kualitas hidup pasien epilepsi anak. Sari Pediatri 2020;22(4):230-5

Kata kunci: epilepsi, kualitas hidup, pendapatan orangtua

\section{The Impact of Parents Income on the Quality of Life of Pediatric Epilepsy Patients}

Monika Putri Gratia, Fadhilah Tia Nur, Muhammad Riza

Background. Quality of life is related to the health condition of the person. Children with epilepsy tend to have a poor quality of life. Many factors are involved in the quality of life of pediatric epilepsy patients one of which is family demographic include parents' income. Objective. Knowing and researching the impact of parents' income on the quality of life of pediatric epilepsy patients by using the PedsQL questionnaire.

Methods. This study was analytic observational research with the cross sectional approach. Sampling was carried out at the Wijaya Kusuma pediatric polyclinic at Hospital Dr. Moewardi, involving interviews with 50 epilepsy patients and their parents.

Result. Most epilepsy patients (66.0\%) have a low quality of life. The impact of parents' income was stated to be not statistically significant $(\mathrm{p}=0.281)$. Quality of life of pediatric epilepsy patients was influenced by the number of AED's theraphy and the membership of BPJS ( $\mathrm{p}=0,001 ; \mathrm{p}=0,040)$.

Conclusion. Parents' income has no impact on the quality of life of pediatric epilepsy patients. Sari Pediatri 2020;22(4):230-5

Keywords: epilepsy, quality of life, parents income

Alamat korespondensi: Monika Putri Gratia. Departemen Ilmu Kesehatan Anak Fakultas Kedokteran Universitas Sebelas Maret/RS Dr Moewardi, Surakarta. Email: gratiamonika@gmail.com 
$\mathrm{K}$ ualitashidup seseorang memiliki keterkaitan dengan kondisi kesehatannya. Epilepsi merupakan salah satu penyakit saraf kronis hidup. Pada pasienepilepsil kualitas hidup dibanding orang normal,1,2 seperti kesulitan belajar, ketidakstabilan emosi, perubahan perilaku, fungsi sosial yang rendah, dan gangguan perkembangan.1-4 Seorang pasien epilepsi juga kerap memiliki kecemasan, yaitu berupa ketakutan pasien untuk beraktivitas karena kemungkinan kejang muncul tiba-tiba.5 Ditambah lagi persepsi masyarakat yang belum sepenuhnya memahami tentang kasus epilepsi memunculkan diskriminasi terhadap penderita epilepsi sehingga meningkatkan risiko terjadinya depresi. ${ }^{3}$

Kualitas hidup yang rendah pasien epilepsi anak dipengaruhi oleh beragam faktor. Keadaan klinis pasien, seperti tipe, etiologi, onset, dan frekuensi kejang serta adanya komorbid penyerta dapat berpengaruh pada fungsi neurologis pasien sehingga memengaruhi anak secara kognitif dan tumbuh kembangnya. ${ }^{6-8}$ Tata laksana yang diterima pasien epilepsi tentunya memengaruhi perbaikan kondisi klinis pasien. Di sisi lain, beberapa ob a t antiepilepsi (OAE) mungkin memunculkan efek samping pada sebagian pasien.9-12

Dampak emosional pasien bahkan dapat memunculkan depresi karena keadaan pasien itu sendiri, psikososial, dan kondisi lingkungan di masyarakat yang kerap melabeli penderita epilepsi dengan stigma. ${ }^{3}$ Terlebih dalam lingkup keluarga karena keluarga memiliki peran penting dalam kemampuan adaptasi anak. Pola asuh dalam keluarga menjadi variabel penting yang memengaruhi psikososial anak. ${ }^{8}$ Di sisi lain, besar pendapatan keluarga dianggap berpengaruh pada proses pengobatan yang dijalani anak pasien epilepsi. Semakin tinggi pendapatan keluarga, pengobatan semakin teratur sehingga frekuensi kejang lebih terkontrol. ${ }^{4}$

Penurunan kualitas hidup tidak hanya memengaruhi kehidupan pasien epilepsi di usia muda, tetapi juga bisa memengaruhi pasien hingga beranjak dewasa. Pemahaman kualitas hidup pasien epilepsi bisa menuntun dalam pembuatan keputusan tata laksana yang akan dilakukan. ${ }^{3}$

\section{Metode}

Penelitian yang dilakukan merupakan jenis penelitian observasional analitik dengan pendekatan potong lintang. Penelitian dilakukan sepanjang Oktober 2018 di poli saraf anak Wijaya Kusuma RSUD Dr. Moewardi Surakarta. Penelitian ini telah dinyatakan laik etik oleh KEPK Fakultas Kedokteran Universitas Sebelas Maret.

Pengambilan sampel dilakukan menggunakan teknik consecutive sampling dengan wawancara langsung kepada 50 pasien epilepsi anak beserta orangtua. Subjek yang dipilih adalah pasien epilepsi anak rentang usia 2-18 tahun yang bersedia ikut serta dalam penelitian dan menjawab kuesioner dan formulir data dengan lengkap.

Data yang dikumpulkan meliputi usia, jenis kelamin, jenis epilepsi, jenis pemberian OAE, kepesertaan Badan Penyelenggara Jam in an Sosial (BPJS) Kesehatan, usia orangtua, pendapatan orangtua perbulan, dan kualitas hidup pasien. Rata- rata pendapatan orangtua dalam tiap bulannya diklasifikasikan berdasarkan lebih besar atau lebih kecil dari UMR Surakarta tahun 2018, yaitu sebesar Rp1.668.700,00. Kualitas hidup pasien epilepsi anak dinilai menggunakan kuisioner PedsQL 4.0 dalam Bahasa Indonesia yang telah diuji dan dipakai oleh penelitian sebelumnya dan memiliki reliabilitias yang baik dengan nilai Alfa Cronbach 0,835.14

Data yang terkumpul dalam penelitian diolah menggunakan program SPSS ${ }^{\oplus} 22$. Uji normalitas data menggunakan uji Kolmogorov-Smirnov. Untuk menentukan hubungan antar variabel, analisis bivariat menggunakan uji Korelasi Spearman dan analisis multivariat menggunakan uji regresi linier berganda.

\section{Hasil}

Dari 96 pasien epilepsi yang melakukan pemeriksaan di poli saraf anak Wijaya Kusuma RSUD Dr. Moewardi Surakarta selama bulan Oktober, didapatkan 50 sampel yang bersedia mengisi kuisioner dan telah memenuhi kriteria penelitian. Berikut ini adalah hasil penelitian yang tertera pada Tabel 1 . 
Tabel 1. Karakteristik sampel penelitian

\begin{tabular}{|c|c|c|c|c|c|c|}
\hline & Frekuensi (n) & $\%$ & Min-Max & Mean \pm SD & $\mathrm{p}$ & $\mathrm{r}$ \\
\hline \multicolumn{7}{|c|}{ Usia anak (tahun) } \\
\hline $2-4$ & 27 & 54 & $2-18$ & $5,84 \pm 4,51$ & & \\
\hline $5-7$ & 12 & 24 & & & & \\
\hline $8-12$ & 4 & 8 & & & & \\
\hline $13-18$ & 7 & 14 & & & & \\
\hline \multicolumn{7}{|l|}{ Jenis kelamin } \\
\hline Laki-laki & 24 & 48 & & & & \\
\hline Perempuan & 26 & 52 & & & & \\
\hline \multicolumn{7}{|l|}{ Jenis epilepsi $^{* *}$} \\
\hline Umum & 41 & 82 & & & 0,122 & $-0,168$ \\
\hline Parsial & 9 & 18 & & & & \\
\hline \multicolumn{7}{|c|}{ Jenis pemberian $\mathrm{OAE}^{* *}$} \\
\hline Monoterapi & 33 & 66 & & & 0,001 & $-0,422$ \\
\hline Politerapi & 17 & 34 & & & & \\
\hline \multicolumn{7}{|c|}{ Kepesertaan BPJS ${ }^{* *}$} \\
\hline BPJS & 48 & 96 & & & 0,040 & $-0,250$ \\
\hline Umum & 2 & 4 & & & & \\
\hline \multicolumn{7}{|c|}{ Usia orangtua/ pengasuh"* (tahun) } \\
\hline $20-29$ & 10 & 20 & $25-55$ & $35,50 \pm 7,24$ & 0,187 & 0,128 \\
\hline $30-39$ & 29 & 58 & & & & \\
\hline $40-49$ & 8 & 16 & & & & \\
\hline $50-59$ & 3 & 6 & & & & \\
\hline \multicolumn{7}{|c|}{ Pendapatan orangtua* } \\
\hline$<\mathrm{UMR}$ & 25 & 50 & Rp900.000- & Rp2.072.000 \pm & 0,281 & 0,155 \\
\hline >UMR & 25 & 50 & Rp8.000.000 & Rp1377.67 & & \\
\hline \multicolumn{7}{|c|}{ Kualitas hidup (PedsQL) } \\
\hline $40-49$ & 19 & 38 & $40-88$ & $64,50 \pm 15,20$ & & \\
\hline $50-59$ & 3 & 6 & & & & \\
\hline $60-69$ & 11 & 22 & & & & \\
\hline $70-79$ & 13 & 26 & & & & \\
\hline $80-89$ & 4 & 8 & & & & \\
\hline
\end{tabular}

${ }^{*}$ Analisis bivariat menggunakan uji Korelasi Spearman karena distribusi sebaran data tidak normal $(\mathrm{p}=0,015)$.

**Analisis multivariat terhadap kualitas hidup pasien menggunakan uji regresi linier berganda.

UMR: upah minimum regional

Dari 50 sampel, pasien epilepsi anak memiliki skor PedsQL beragam, tetapi dominan memiliki skor yang rendah bila dibandingkan dengan rata-rata skor PedsQL pada anak normal $(<70)$. Pada variabel pendapatan orangtua, sampel penelitian terbagi merata dalam 2 kelompok yaitu kelompok dengan pendapatan orangtua lebih besar dari UMR Surakarta tahun 2018 dan kelompok dengan pendapatan orangtua lebih kecil dari UMR Surakarta tahun 2018.

Hasil uji analisis bivariat, variabel pendapatan orangtua tidak signifikan berpengaruh terhadap kualitas hidup pasien epilepsi anak secara statistik. Pada analisis multivariat untuk variabel perancu yang diteliti, didapatkan jenis pemberian OAT dan kepesertaan BPJS memberi pengaruh yang cukup signifikan terhadap kualitas hidup pasien epilepsi anak. 


\section{Pembahasan}

Pada anak dengan penyakit kronis seperti epilepsi, rentan mengalami perburukan kualitas hidup. ${ }^{2,15}$ Hal tersebut juga terlihat pada hasil penelitian kami, sebagian besar (66\%) memiliki skor PedsQL yang rendah. Pasien epilepsi kerap mengalami gangguan perkembangan, kognitif, emosional, psikologis, fungsi sosial, dan perubahan perilaku.3,16-18

Berdaarkan penelitian kami, besar pendapatan orangtua tidak memberikan pengaruh bermakna pada kualitas hidup pasien epilepsi anak yang menjadi subjek penelitian. Terdapat penelitian sebelumnya yang mencari faktor yang memengaruhi kualitas hidup anak epilepsi dengan hasil yang berbeda. Dalam penelitian yang menggunakan instrumen QOLCE, meskipun tidak memengaruhi kualitas hidup anak secara keseluruhan, pada kelompok orangtua berpenghasilan baik, a nak cenderung memiliki kepercayaan diri yang lebih baik dan dapat berpengaruh pada fungsi emosional. Semakin tinggi riwayat pendidikan dan pendapatan keluarga, pengobatan berlangsung rutin. Dengan demikian, perbaikan fungsi neurologis pasien dapat tercapai, Indikator tersebut terlihat pada kondisi klinis pasien yaitu frekuensi kejang lebih terkontrol. Pasien pun menjadi lebih percaya diri dan kecemasan dalam beraktivitas berkurang. ${ }^{4}$ Adapula penelitian yang melaporkan hal serupa dengan hasil penelitian kami bahwa demografis keluarga tidak menjadi faktor yang berpengaruh pada kualitas hidup anak epilepsi. ${ }^{1,16}$

Pengaruh pendapatan orangtua terhadap kualitas hidup pasien epilepsi anak dalam penelitian kami tidak bermakna $\mathrm{k}$ a r e $\mathrm{n}$ a disebabkan adanya variabel perancu lain. Dalam hal ini, jenis pemberian OAE dan kepesertaan BPJS menjadi faktor yang dianggap memberi pengaruh. Sementara variabel perancu lain, seperti jenis epilepsi dan usia orangtua tidak menunjukkan adanya pengaruh bermakna terhadap kualitas hidup.

Dari hasil penelitian terdapat pengaruh dari jenis pemberian OAE terhadap kualitas hidup pasien epilepsi anak, dengan tingkat korelasi sedang bernilai negatif. Hal ini berarti pengobatan secara monoterapi memberi pengaruh yang lebih baik terhadap kualitas hidup pasien dibanding pengobatan secara politerapi. Sebelumnya, berbagai penelitian memang melaporkan adanya pengaruh jenis pemberian OAE pada kualitas hidup pasien, tetapi terdapat pengaruh yang bervariasi antar penelitian. Sebagian melaporkan bahwa pengobatan epilepsi secara politerapi dinilai mendorong perbaikan kualitas hidup pasien. 19,20 Dikatakan pula pada pasien epilepsi intraktabel pengobatan secara politerapi mampu menrunkan frekuensi kejang yang nanti dapat memengaruhi kualitas hidup pasien. ${ }^{20}$ Sebagian lagi melaporkan hasil seperti hasil penelitian kami bahwa pada pasien yang mendapat pengobatan secara monoterapi memiliki skor kualitas hidup yang lebih baik dibanding paisen yang mendapat pengobatan secara politerapi.10,16 Beberpa jenis OAE dapat memunculkan efek samping pada pasien, seperti gangguan terkait sistem saraf pusat, penurunan aktivitas motorik dan psikomoorik, daya ingat rendah, dan sulit berkonsentrasi. ${ }^{16,21}$ Penambahan terapi pada pasien epilepsi pada umumnya dilakukan karena monoterapi dianggap tidak efektif untuk memunculkan perbaikan yang adekuat pada pasien, meskipun bebas kejang merupakan tujuan penting dalam pengobatan epilepsi, efek samping obat serta pengaruh terhadap kualitas hidup pasien juga perlu menjadi perhatian. 10,16,22

Kepesertaan BPJS kesehatan membantu pengobatan pasien epilepsi anak sehingga tidak hanya bergantung pada faktor kondisi sosial ekonomi keluarga Menurut laporan penelitian Saing, ${ }^{23}$ masalah keuangan menjadi alasan yang menyebabkan ketidakteraturan pengobatan pada 20\% sampel yang diuji. Pogram Prolanis (program pengelolaan penyakit kronis) oleh BPJS, mencantumkan epilepsi sebagai salah satu penyakit yang masuk dalam program tersebut karena memiliki keterkaitan dengan 2 dari 8 dimensi kualitas hidup berdasarkan kuesioner SF-36.

Dalam penelitian tersebut, Prolanis efektif dalam meningkatkan kualitas hidup pasien dalam dimensi fungsi fisik dan dimensi nyeri tubuh. Hasil ini berbeda dengan hasil yang didapat dalam penelitian kami, kepesertaan BPJS justru menjadi faktor negatif pada skor kualitas hidup pasien epilepsi anak. Hal ini mungkin saja terjadi dikarenakan distribusi sampel yang tidak seimbang. Hampir seluruh subjek (96\%) merupakan peserta BPJS, hanya 2 dari 50 anak yang melakukan pengobatan dengan biaya pribadi, sehingga hasil penelitian kami belum dapat memberikan gambaran yang cukup untuk kelompok non-BPJS. Namun, berpengaruhnya kepesertaan BPJS tehadap kualitas hidup menjadi salah satu alasan 
penguat ketidak bermaknaan pengaruh variabel tingkat pendapatan orangtua terhadap kualitas hidup pasien epilepsi anak.

Penelitian kami memiliki beberapa keterbatasan, yaitu terdapat banyak variabel perancu yang tidak dieksklusi sehingga memungkinkan bias dalam menilai pengaruh variabel bebas utama, pendapatan orangtua, terhadap kualitas hidup pasien epilepsi anak. Ditambah lagi orangtua cenderung menutupi riwayat total penghasilan mereka meskipun peneliti telah berusaha menjelaskan tujuan dari penelitian ini. Pihak orangtua hanya bersedia memberikan perkiraan rentang pendapatan dalam tiap bulannya sehingga memungkinkan adanya bias pada data variabel pendapatan orangtua. Penelitian kami juga melibatkan anak dan orangtuanya dalam menilai kualitas hidup pasien agar mendapatkan sudut pandang yang lebih lengkap. Sayangnya, sebagian anak tidak mampu menjawab kuesioner secara kooperatif sehingga pada sebagian subjek penilaian kualitas hidup ditentukan berdasarkan sudut pandang orangtua saja. Selain itu, sampai saat ini, belum disepakati batas klasifikasi skor PedsQL yang menentukan kulitas hidup baik atau buruk terkhusus pada pasien epilepsi.

\section{Kesimpulan}

Tidak terdapat pengaruh bermakna dari pendapatan orangtua terhadap kualitas hidup pasien epilepsi anak.

\section{Daftar pustaka}

1. Haneef Z, Grant ML, Valencia I, dkk. Correlation between child and parental perceptions of health-related quality of life in epilepsy using the PedsQL.v4.0 measurement model. Epileptic Disord 2010;12:275-82.

2. Gholami A, Salarilak S, Lotfabadi P, dkk. Quality of life in epileptic patients compared with healthy people. MJIRI 2015;29:388-94.

3. Ronen GM, Streiner DL, Verhey LH, dkk. Disease characteristics and psychosocial factors: Explaining the expression of quality of life in childhood epilepsy. Epilepsy Behav 2010;18:88-93.

4. Wishwadewa WN, Mangunatmadja I, Said M, Firmansyah A, Soedjatmiko S, Tridjaja B. Kualitas hidup anak epilepsi dan faktor-faktor yang memengaruhi di departemen Ilmu Kesehatan Anak FKUI/ RSCM Jakarta. Sari Pediatri 2016;10:272-9.
5. Jacoby A, Baker GA. Quality-of-life trajectories in epilepsy: A review of the literature. Epilepsy Behav 2008;12:557-71.

6. Ashjazadeh N, Yadollahikhales G, Ayoobzadehshirazi A, Sadraii N, Hadi N. Comparison of the health-related quality of life between epileptic patients with partial and generalized seizure. Iran J Neurol 2014;13:94-100.

7. Blond BN, Detyniecki K, Hirsch LJ. Assessment of treatment side effects and quality of life in people with epilepsy. Neurol Clin 2016; 34:395-410.

8. Fong CY, Chang WM, Kong AN, Rithauddin AM, Khoo TB, Ong LC. Quality of life in Malaysian children with epilepsy. Epilepsy Behav 2018;80:15-20.

9. Canuet L, Ishii R, Iwase M, dkk. Factors associated with impaired quality of life in younger and older adults with epilepsy. Epilepsy Res 2009;83:58-65..

10. Elsharkawy AE, Thorbecke R, Ebner A, May TW. Determinants of quality of life in patients with refractory focal epilepsy who were not eligible for surgery or who rejected surgery. Epilepsy Behav 2012;24:249-55.

11. Hamid H, Blackmon K, Cong X, dkk. Mood, anxiety, and incomplete seizure control affect quality of life after epilepsy surgery. Neurology 2014;82:887-94.

12. Luoni C, Bisulli F, Canevini MP, dkk. Determinants of health-related quality of life in pharmacoresistant epilepsy: Results from a large multicenter study of consecutively enrolled patients using validated quantitative assessments: Quality of Life in Pharmacoresistant Epilepsy. Epilepsia 2011;52:2181-91.

13. Mezgebe M, Akhtar-Danesh GG, Streiner DL, Fayed N, Rosenbaum PL, Ronen GM. Quality of life in children with epilepsy: How does it compare with the quality of life in typical children and children with cerebral palsy? Epilepsy Behav 2015;52:239-43.

14. Aji DN, Silman C, Aryudi C, dkk. Faktor-faktor yang berhubungan dengan kualitas hidup pasien thalassemia mayor di pusat thalassemia departemen Ilmu Kesehatan Anak RSCM. Sari Pediatri 2016;11:85-89.

15. Moreira H, Carona C, Silva N, Frontini R, Bullinger M, Canavarro MC. Psychological and quality of life outcomes in pediatric populations:a parent-child perspective. J Pediatr 2013; 163:1471-8

16. Auriel E, Landov H, Blatt I, dkk. Quality of life in seizurefree patients with epilepsy on monotheraphy. Epilepsy Behav 2009;14:130-3.

17. Dakwa FE, Mudyahoto T. Impact of epilepsy on children's academic performance. IJARPED 2013;2:359-65.

18. Suwarba IGNM. Insidens dan karakteristik klinis epilepsi pada anak. Sari Pediatri 2011;13:123-8.

19. Piperidou C, Karlovasitou A, Triantafyllou N, dkk. Association of demographic, clinical and treatment variables with quality of life of patients with epilepsy in Greece. Quality of Life Research 2008;17:987-96.

20. Dash D, Aggarwal V, Joshi R, Padma MV, Tripathi M. Effect of reduction of antiepileptic drugs in patients with drugrefractory epilepsy. Seizure 2015;27:25-9.

21. Mustarsid, Nur FT, Setiawat SR, Salimo H. Pengaruh obat 
Monika Putri Gratia dkk: Pengaruh pendapatan orangtua terhadap kualitas hidup pasien epilepsi anak

anti epilepsi terhadap daya ingat pada epilepsi anak. Sari Pediatri 2011;12:302-6.

22. Dang LT, Silverstein FS. Drug treatment of seizures and epilepsy in newborns and children. Pediatr. Clin. North Am
2017;64:1291-308.

23. Saing JH. Tingkat pengetahuan, perilaku, dan kepatuhan berobat orangtua dari pasien epilepsi anak di Medan. Sari Pediatri 2010;12:103-7. 